\title{
Deficits in Trace Fear Memory and Long-Term Potentiation in a Mouse Model for Fragile X Syndrome
}

\author{
Ming-Gao Zhao, ${ }^{*}$ Hiroki Toyoda, ${ }^{*}$ Shanelle W. Ko, Hoi-Ki Ding, Long-Jun Wu, and Min Zhuo \\ Department of Physiology, Faculty of Medicine, University of Toronto, Toronto, Ontario, Canada M5S 1A8
}

Trace fear memory requires the activity of the anterior cingulate cortex (ACC) and is sensitive to attention-distracting stimuli. Fragile $\mathrm{X}$ syndrome is the most common form of mental retardation with many patients exhibiting attention deficits. Previous studies in fragile $\mathrm{X}$ mental retardation 1 (FMR1) knock-out (KO) mice, a mouse model for fragile X, focused mainly on hippocampal-dependent plasticity and spatial memory. We demonstrate that FMR1 knock-out mice show a defect in trace fear memory without changes in locomotion, anxiety, and pain sensitivity. Whole-cell path-clamp recordings in the ACC show that long-term potentiation (LTP) was completely abolished. A similar decrease in LTP was found in the lateral amygdala, another structure implicated in fear memory. No significant changes were found in basal synaptic transmission. This suggests that synaptic plasticity in the ACC and amygdala of FMR1 KO mice plays an important role in the expression of behavioral phenotypes similar to the symptoms of fragile X syndrome.

Key words: trace fear memory; long-term potentiation; cingulate cortex; amygdala; fragile $\mathrm{X}$ syndrome; attention

\section{Introduction}

Fragile X syndrome is the most common form of inherited mental retardation, characterized by moderate-to-severe mental retardation, attention deficits, and anxiety. This disease results from the expansion of a trinucleotide repeat (CGG) within the $\mathrm{X}$-linked fragile X mental retardation 1 (FMR1) gene (Pieretti et al., 1991; Eichler et al., 1994; Siomi et al., 1994; Feng et al., 1995). As a result of this expansion, the product of the FMR1 gene, fragile $\mathrm{X}$ mental retardation protein (FMRP), is not expressed (Oberle et al., 1991; Verkerk et al., 1991; Kooy, 2003). FMRP is an mRNA binding protein that is associated with polyribosomes and is thought to be involved in the translational efficiency and/or trafficking of certain mRNAs (Jin and Warren, 2003; Willemsen et al., 2004).

A myriad of studies have defined spatial and associative learning deficits in FMR1 knock-out (KO) mice. Mild spatial learning deficits are reported, although the role of FMR1 in fear conditioning remains elusive (Table 1). Some studies report intact contextual fear memory (Van Dam et al., 2000), whereas others report deficits in both auditory and contextual fear conditioning ( $\mathrm{Pa}-$ radee et al., 1999). Classic conditioning paradigms typically use delay conditioning in which the conditioned stimulus (CS) is

\footnotetext{
Received April 18, 2005; revised June 21, 2005; accepted July 1, 2005.

This work was supported by grants from the EJLB-Canadian Institutes of Health Research Michael Smith Chair in Neurosciences and Mental Health, Canada Research Chair, and NeuroCanada to M.Z. M.-G.Z. was supported by a postdoctoral fellowship from the Fragile X Research Foundation of Canada. We thank Dr. W. T. Greenough for his generous gift of FMR1 wild-type and knock-out breeding pairs. We also thank Aaron Grossman for his help in coordinating the shipment of FMR1 mice.

${ }^{*}$ M. G.Z. and H.T. contributed equally to this work.

Correspondence should be addressed to Dr. Min Zhuo, Department of Physiology, Faculty of Medicine, University of Toronto, Medical Science Building, Room 3342, 1 King's College Circle, Toronto, Ontario, Canada M5S 1A8. E-mail: min.zhuo@utoronto.ca.

DOI:10.1523/JNEUROSCI.1520-05.2005

Copyright $\odot 2005$ Society for Neuroscience $\quad$ 0270-6474/05/257385-08\$15.00/0
}

immediately followed by or coterminates with an unconditioned stimulus (US). In contrast, trace fear conditioning introduces the US a certain time interval after the CS.

Recent studies have highlighted the difference between trace and delay fear conditioning. Trace fear memory, but not delay, requires both attention and the anterior cingulate cortex (ACC) in mice (Han et al., 2003). In humans, attention-distracting stimuli interfere with trace but not delay conditioning (Clark and Squire, 1998; Manns et al., 2000). Because many children with fragile $\mathrm{X}$ are diagnosed with attention deficit/hyperactivity disorder (ADHD) (Hagerman et al., 1996; Cornish et al., 2004), we hypothesized that this form of associative learning may be disrupted in FMR1 KO mice and alterations in synaptic plasticity within the ACC may underlie any observed deficits.

Protein synthesis is considered an important component of synaptic plasticity. FMRP is believed to regulate protein synthesis in synapses by providing a local source of newly synthesized proteins (Jin and Warren, 2003). Long-term potentiation (LTP), a type of long-lasting synaptic plasticity, is believed to be involved in learning and memory (Bliss and Collingridge, 1993; Malenka and Nicoll, 1993). Four studies showed that LTP in the CA1 region of the hippocampus was unaltered in FMR1 KO mice (Godfraind et al., 1996; Paradee et al., 1999; Huber et al., 2002; Li et al., 2002). Because LTP plays a role in learning and memory, abnormalities in its formation should correlate with cognitive deficits observed in fragile X. However, no study to date has directly related learning and memory deficits to changes in synaptic plasticity in FMR1 KO mice in brain regions outside of the hippocampus.

Here, we show that FMR1 KO mice have a defect in trace fear memory and that LTP was decreased in the ACC and lateral amygdala (LA), whereas short-term synaptic plasticity was normal. 


\section{Materials and Methods}

Animals. For behavioral experiments, male mice were at least 8 weeks of age. FMR1 wildtype (WT) and KO mice of the FVB.129P2$F m r 1^{t m 1 C g r}$ strain were generously provided by Dr. W. T. Greenough (Los Angeles, CA). In this "sighted" strain, the Pde6b gene, which in a mutated form codes for retinal degeneration in FVB mice, has been selectively replaced by crossing with strains carrying the nondefective allele (Weiler et al., 2004). All mice were housed under a $12 \mathrm{~h}$ light/dark cycle with food and water provided ad libitum. The Animal Care and Use Committee of University of Toronto approved all mouse protocols.

Behavioral tests. Trace fear conditioning was performed in an isolated shock chamber (Med Associates, St. Albans, VT). The CS used was an $80 \mathrm{~dB}$ white noise, delivered for $15 \mathrm{~s}$, and the US was a $0.7 \mathrm{~mA}$ scrambled footshock for $0.5 \mathrm{~s}$. Mice were acclimated for $60 \mathrm{~s}$ and were presented with 10 CS-trace-US intertrial interval (ITI) trials (trace, $30 \mathrm{~s}$; ITI, $210 \mathrm{~s}$ ). One day after training, mice were acclimated for $60 \mathrm{~s}$ followed by 10 CS-ITI trials (ITI, $210 \mathrm{~s}$ ) in a novel chamber to test for trace fear memory (Huerta et al., 2000). All data were video recorded using FreezeFrame Video-Based Conditioned Fear System and analyzed by Actimetrics Software (Coulbourn Instruments, Wilmette, IL). Average freezing for the baseline and for each ITI during the training and testing sessions was analyzed. Bouts of $1.0 \mathrm{~s}$ were used to define freezing. Locomotor activity was measured using the open-field activity monitor $(43.2 \times 43.2 \times 30.5$ $\mathrm{cm}$; Med Associates). Mice were placed in the center of the open field, and activity was measured for $30 \mathrm{~min}$. In the hotplate test, mice were placed on a standard thermal hotplate with a $10 \times 10$ inch black heated surface set at 50 or $55^{\circ} \mathrm{C}$ (Columbus Instruments, Columbus, $\mathrm{OH}$ ). The latency in which the mice showed signs of nociception, by either rapid fanning or licking of the hindpaws, was recorded with a cutoff time of $30 \mathrm{~s}$. The spinal nociceptive tail-flick reflex was evoked by radiant heat (Columbus Instruments) applied to the underside of the tail. The latency to reflexive removal of the tail away from the heat was measured by a photocell timer. A cutoff time of $10 \mathrm{~s}$ was used to minimize skin damage. To test for anxiety-like behavior, mice were placed in the center of a black, Plexiglas Elevated Plus Maze for 5 min (Med Associates). The time spent in the open and closed arms was measured, and the percentage of time spent in the open arms was calculated and analyzed for anxiety-like behavior.

Slice preparation. Coronal brain slices $(300 \mu \mathrm{M})$ from 6- to 8-week-old FMR1 WT and KO mice, containing the ACC or LA, were prepared using standard methods (Ko et al., 2005). Slices were transferred to a submerged recovery chamber with oxygenated $\left(95 \% \mathrm{O}_{2}\right.$ and $\left.5 \% \mathrm{CO}_{2}\right)$ artificial CSF (ACSF) containing the following (in mM): $124 \mathrm{NaCl}, 4.4 \mathrm{KCl}, 2$ $\mathrm{CaCl}_{2}, 1 \mathrm{MgSO}_{4}, 25 \mathrm{NaHCO}_{3}, 1 \mathrm{NaH}_{2} \mathrm{PO}_{4}$, and 10 glucose, at room temperature for at least $1 \mathrm{~h}$.

Whole-cell recordings. Experiments were performed in a recording chamber on the stage of an Axioskop 2FS microscope with infrared differential interference contrast optics for visualization of whole-cell patch-clamp recording. In ACC slices, EPSCs were recorded from layer II-III pyramidal neurons with an Axon 200B amplifier (Molecular Devices, Palo Alto, CA) and the stimulations were delivered by a bipolar tungsten stimulating electrode placed in layer $\mathrm{V}$ of the ACC. We recorded EPSCs from neurons in layers II-III of the ACC, because layer II-III pyramidal neurons are reported to be the major location of intracortical horizontal pathways (Hess et al., 1994), and the superficial layers of the ACC receive substantial glutamate input (Wei et al., 1999). In LA slices,
EPSCs in pyramidal neurons were evoked by stimulating the thalamic input delivered through a tungsten bipolar electrode. AMPA receptormediated EPSCs were induced by repetitive stimulations at $0.02 \mathrm{~Hz}$, and neurons were voltage clamped at $-70 \mathrm{mV}$. We identified pyramidal neurons by injecting depolarized currents into neurons to induce action potentials. The typical firing pattern of a pyramidal neuron showed significant firing frequency adaptation, whereas the pattern in an interneuron showed fast-spiking action potentials followed by pronounced hyperpolarization. After obtaining stable EPSCs for at least $10 \mathrm{~min}$, LTP was induced by 80 pulses at $2 \mathrm{~Hz}$ paired with postsynaptic depolarization at $+30 \mathrm{mV}$. The recording pipettes (3-5 M $\Omega$ ) were filled with solution containing the following (in $\mathrm{mM}$ ): $145 \mathrm{~K}$-gluconate, $5 \mathrm{NaCl}, 1 \mathrm{MgCl}_{2}, 0.2$ EGTA, 10 HEPES, $2 \mathrm{Mg}$-ATP, and $0.1 \mathrm{Na}_{3}$-GTP, adjusted to $\mathrm{pH} 7.2$ with KOH. The NMDA receptor (NMDAR)-mediated component of EPSCs was pharmacologically isolated in $\mathrm{Mg}^{2+}$-free ACSF containing the following (in $\mu \mathrm{M}$ ): $20 \mathrm{CNQX}, 1$ glycine, and 100 picrotoxin. The patch electrodes contained the following (in $\mathrm{mM}$ ): 102 cesium gluconate, 5 TEA-chloride, $3.7 \mathrm{NaCl}$, 10 BAPTA, 0.2 EGTA, 20 HEPES, 2 Mg-ATP, $0.3 \mathrm{Na}$-GTP, and 5 QX-314 chloride [ $\mathrm{N}$-(2,6-dimethylphenylcarbamoylmethyl)triethylammonium chloride], adjusted to $\mathrm{pH} 7.2$ with $\mathrm{CsOH}$. Neurons were voltage clamped at $-60 \mathrm{mV}$, and NMDAR-mediated EPSCs were evoked at $0.05 \mathrm{~Hz}$. [ $(R)$-[( $S)$-1-(4-bromo-phenyl)-ethylamino]-(2,3-dioxo-1,2,3,4-tetrahydro-quinoxalin-5-yl)-methyl]phosphonic acid (NVP-AAM077) and $R$ - $(R, S)$ - $\alpha$-(4-hydroxyphenyl)- $\beta$-methyl-4(phenylmethyl)-1-piperidine propranol (Ro25-6981) were bath applied sequentially to assess the NMDA receptor 2A (NR2A) and NR2B components of EPSCs. Picrotoxin $(100 \mu \mathrm{M})$ was always present to block $\mathrm{GABA}_{\mathrm{A}}$ receptor-mediated inhibitory synaptic currents. Access resistance was $15-30 \mathrm{M} \Omega$ and monitored throughout the experiment. Data were discarded if access resistance changed $>15 \%$ during an experiment.

Data analysis. Results were expressed as mean \pm SEM. Statistical comparisons were performed using one- or two-way ANOVA using the Stu- 
dent-Newman-Keuls test for post hoc comparisons. In all cases, $p<0.05$ was considered statistically significant.

\section{Results}

\section{Impaired trace fear memory in FMR1 KO mice}

To determine whether the cognitive defects of FMR1 KO mice may be related to defects in attention, WT and $\mathrm{KO}$ mice were tested in the trace fear conditioning paradigm. This paradigm differs from the classic delay paradigm in that the animal must sustain attention during the trace interval to learn the CS-US association (Clark and Squire, 1998; Han et al., 2003). The CS, an $80 \mathrm{~dB}$ white noise delivered for $15 \mathrm{~s}$, was delivered $30 \mathrm{~s}$ before (trace) the US, a $0.7 \mathrm{~mA}$ scrambled footshock. Mice were presented with 10 CS-trace-US trials with an ITI of $210 \mathrm{~s}$. One day after training, mice received 10 CS-ITI trials in a novel chamber to test for trace fear memory (Huerta et al., 2000).

Before training, FMR1 KO mice displayed similar baseline freezing compared with FMR1 WT mice (WT, $0.2 \pm 0.2 \%, n=$ 10 ; $\mathrm{KO}, 3.7 \pm 2.3 \%, n=11 ; p=0.17)$. FMR1 WT mice successfully learned the trace fear conditioning after $10 \mathrm{CS}-\mathrm{US}$ pairings and showed increased freezing throughout the training session $(4.8 \pm 2.3 \%$ freezing during ITI- 1 vs $55.8 \pm 5.2 \%$ freezing during ITI-10; $p<0.001)$. Freezing was also increased in FMR1 KO mice after 10 CS-US pairings $(3.7 \pm 1.3 \%$ freezing during ITI- 1 vs $25.2 \pm 6.5 \%$ freezing during ITI-10; $p<0.05)$. However, FMR1 $\mathrm{KO}$ mice displayed significantly reduced freezing compared with FMR1 WT mice, from ITI-5 to ITI-10 (WT, $42.8 \pm 9.7 \%$ freezing during ITI-5; KO, $21.3 \pm 6.3 \%$ freezing during ITI-5; $p<0.05$ ) (Fig. $1 \mathrm{~A}$ ). Additionally, the average freezing during the intertrial intervals was significantly reduced in FMR1 KO mice compared with WT mice (WT, $32.8 \pm 2.5 \%$; KO, $15.0 \pm 1.6 \%$; $p<0.001$ ) (Fig. 1B). Similarly, FMR1 KO mice showed reduced average freezing within the intertrial intervals of the testing session when compared with FMR1 WT mice (WT, $19.1 \pm 1.8 \%$; KO, $10.7 \pm$ $1.4 \% ; p<0.001$ ) (Fig. $1 B$ ). These results suggest that FMR1 KO mice are deficient at acquiring trace fear memory during training as well as in the expression of trace fear memory during testing on the following day.

\section{Normal locomotor activity, nociceptive responses, and anxiety-like behaviors in FMR1 KO mice}

Previous studies have reported alterations in locomotor activity and anxiety levels as a result of the deletion of FMR1 (Peier et al., 2000; Nielsen et al., 2002; Bakker and Oostra, 2003). Because hyperactivity may interfere with the correct recording of the behavioral freezing response, we placed FMR1 WT and KO mice in an open field and recorded their locomotor activity. During the 30 min session, FMR1 KO mice traveled a similar distance compared with FMR1 WT mice (WT, $72.0 \pm 3.9 \mathrm{~m}, n=6$; KO, $65.5 \pm$ $7.1 \mathrm{~m}, n=6 ; p=0.44$ ) (Fig. $1 C$ ). This demonstrates that FMR1 $\mathrm{KO}$ mice have normal locomotor activity and confirms that the reduced freezing seen during trace fear conditioning is not an artifact of hyperactivity. Next, anxiety-like behavior was measured in FMR1 KO and WT mice using the elevated plus maze. There was no difference in the percentage of time spent exploring the open arms of the maze between FMR1 KO mice $(n=7)$ and WT mice $(n=7)$ (data not shown), indicating normal anxietylike behavior in FMR1 KO mice.

To determine whether the decrease in trace fear memory of FMR1 KO mice is attributable to changes in pain sensitivity to the footshock, we measured nociceptive responses in the hotplate and tail-flick tests. No difference was found between nociceptive responses of FMR1 KO and WT mice for the hotplate set at 50 or
A
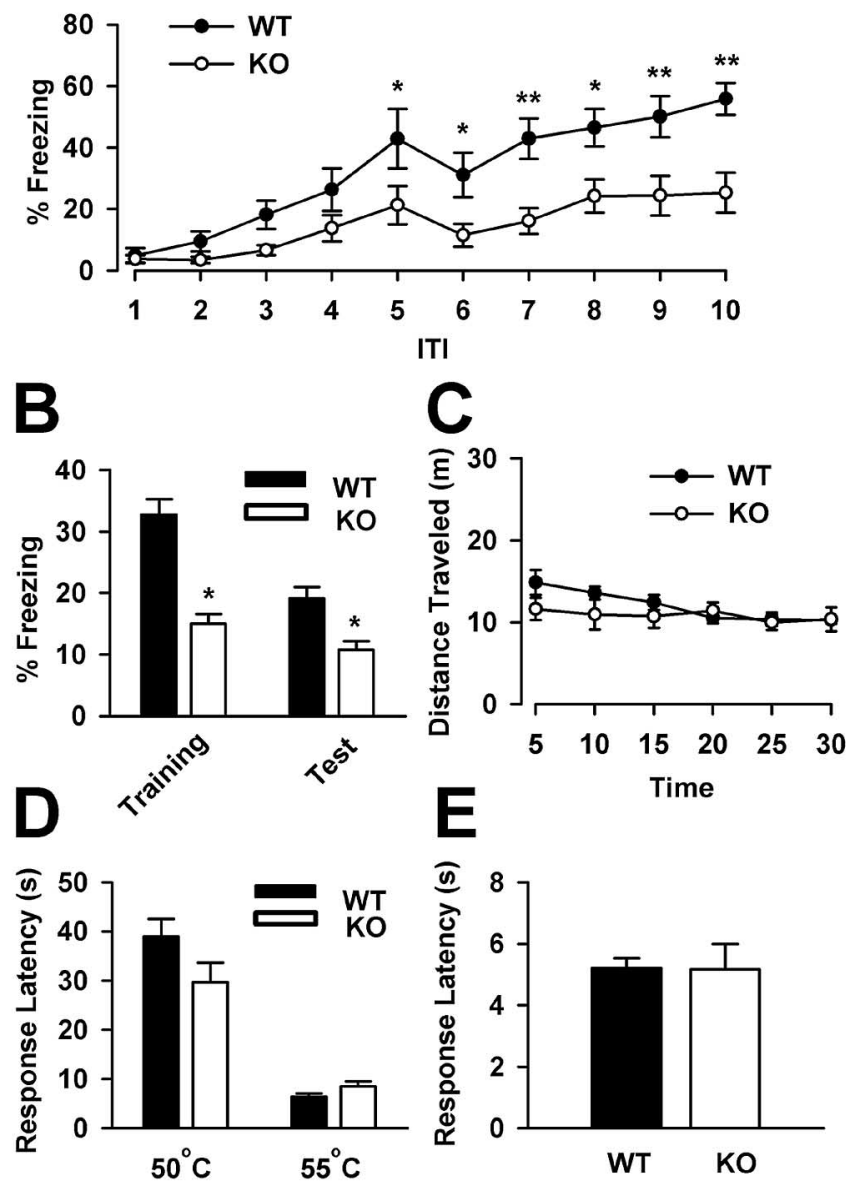

Figure 1. FMR1 K0 mice exhibit impaired trace fear memory. A, FMR1 K0 mice showed significantly reduced freezing during ITI-5 to ITI-10, compared with FMR1 WT mice during trace fear conditioning. $\boldsymbol{B}$, FMR1 K0 mice exhibit reduced average freezing within the intertrial intervals of the training and testing sessions. ${ }^{*} p<0.05,{ }^{* *} p<0.001$, significantly different from the percentage of freezing of FMR1 WT mice $(\boldsymbol{A}, \boldsymbol{B})$. C, FMR1 K0 mice exhibit normal locomotor activity, shown as the distance traveled during $30 \mathrm{~min}$, analyzed in $5 \mathrm{~min}$ bins. $\boldsymbol{D}$, No difference in hotplate response latencies between FMR 1 WT and $K 0$ mice on the 50 and $55^{\circ} \mathrm{C}$ hotplate. $\boldsymbol{E}$, No difference in tail-flick responses was detected between FMR1 WT and KO mice. Error bars indicate SE.

$55^{\circ} \mathrm{C}\left(50^{\circ} \mathrm{C}: \mathrm{WT}, 39.0 \pm 3.5 \mathrm{~s}, n=3 ; \mathrm{KO}, 29.7 \pm 3.9 \mathrm{~s}, n=3 ; p=\right.$ 0.15 ; $55^{\circ} \mathrm{C}$ : WT, $6.4 \pm 0.7 \mathrm{~s}, n=9$; KO, $8.5 \pm 1.0 \mathrm{~s}, n=8 ; p=$ 0.08 ) (Fig. $1 D$ ). Similarly, no difference was found in the tail-flick latency of FMR1 KO compared with WT mice (WT, $5.2 \pm 0.3 \mathrm{~s}$, $n=12 ; \mathrm{KO}, 5.2 \pm 0.8 \mathrm{~s}, n=11 ; p=0.97$ ) (Fig. $1 E$ ). Together, these results suggest that FMR1 KO mice do not have deficits in sensitivity to acute painful stimuli.

\section{Loss of LTP in the ACC and LA in FMR1 KO mice}

Because of the significant reduction of trace fear memory in FMR1 KO mice, we examined synaptic potentiation in the ACC and LA, structures known to be important in learning and fear memory (Frankland et al., 2004; Dityatev and Bolshakov, 2005). First, we performed whole-cell patch-clamp recordings in visually identified pyramidal neurons in layers II-III of ACC slices (Fig. 2A). LTP was induced by pairing presynaptic stimulation with postsynaptic depolarization (see Materials and Methods). The pairing training produced a significant, long-lasting potentiation of synaptic responses in WT mice (mean, $135.9 \pm 8.0 \%$ of 

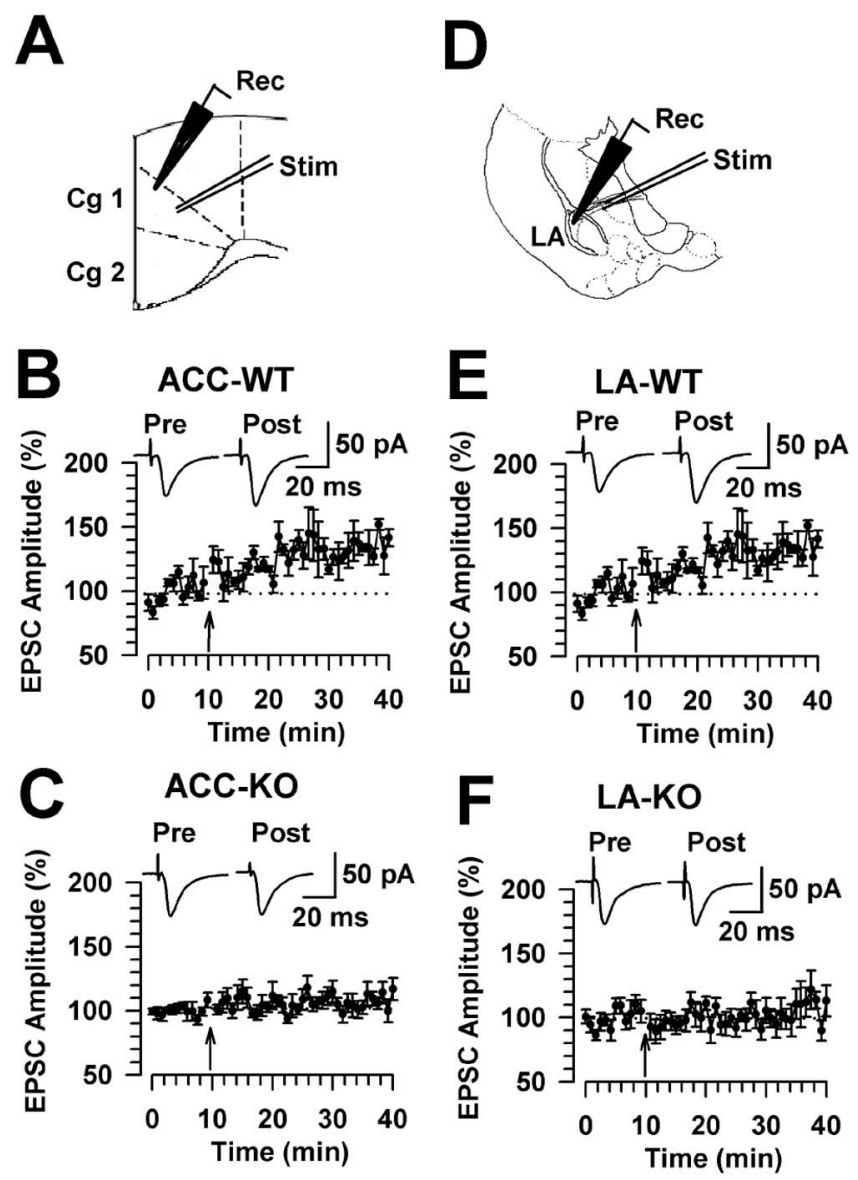

Figure 2. Loss of LTP in the ACC and LA in FMR1 KO mice. A, Diagram of an ACC slice showing the placement of whole-cell patch recording (Rec) and stimulation (Stim) electrodes. LTP was induced by 80 pulses at $2 \mathrm{~Hz}$ with postsynaptic holding at $+30 \mathrm{mV}$. Cg, Cingulate cortex. B, LTP was induced in ACC pyramidal neurons in adult WT mice ( $n=9$ slices $/ 5$ mice). C, LTP was lost in ACC pyramidal neurons of adult $F M R 1$ KO mice ( $n=8$ slices $/ 6$ mice). $D$, Diagram of a slice showing the placement of whole-cell patch recording and stimulation electrode in the LA.E, LTP was induced in LA pyramidal neurons in adult WT mice ( $n=7$ slices $/ 6$ mice). $F$, LTP was lost in LA pyramidal neurons in adult FMR1 K0 mice ( $n=8$ slices/4 mice). The insets show averaged EPSCS at 5 and $25 \mathrm{~min}$ after the pairing procedure (arrows). Error bars indicate SE.

baseline; $n=9$ slices $/ 5$ mice; $p<0.01$ compared with baseline responses before the pairing training) (Fig. $2 B$ ). However, synaptic potentiation in slices of FMR1 KO mice was completely blocked $(109.8 \pm 7.6 \% ; n=8$ slices $/ 6$ mice; $p>0.05$ compared with baseline responses) (Fig. 2C). Next, we examined synaptic potentiation at thalamic input synapses to the LA by placing a stimulating electrode in the ventral striatum (Fig. 2D) (Tsvetkov et al., 2002). In WT mice, the pairing training produced significant synaptic potentiation $(139.0 \pm 5.2 \% ; n=7$ slices $/ 6$ mice; $p<0.01$ compared with baseline) (Fig. 2E). However, synaptic potentiation in slices of FMR1 KO mice was significantly blocked $(110.1 \pm 11.9 \% ; n=8$ slices $/ 4$ mice; $p>0.05$ compared with baseline responses) (Fig. $2 F$ ). These results suggest that FMRP plays a role in the induction of LTP in both the ACC and LA.

Normal short-term synaptic potentiation in FMR1 KO mice In the different regions of the hippocampus, both presynaptic and postsynaptic mechanisms have been proposed to contribute to the expression of LTP (Nicoll and Malenka, 1995). For example, in the CA3 region of the hippocampus, presynaptic expres-
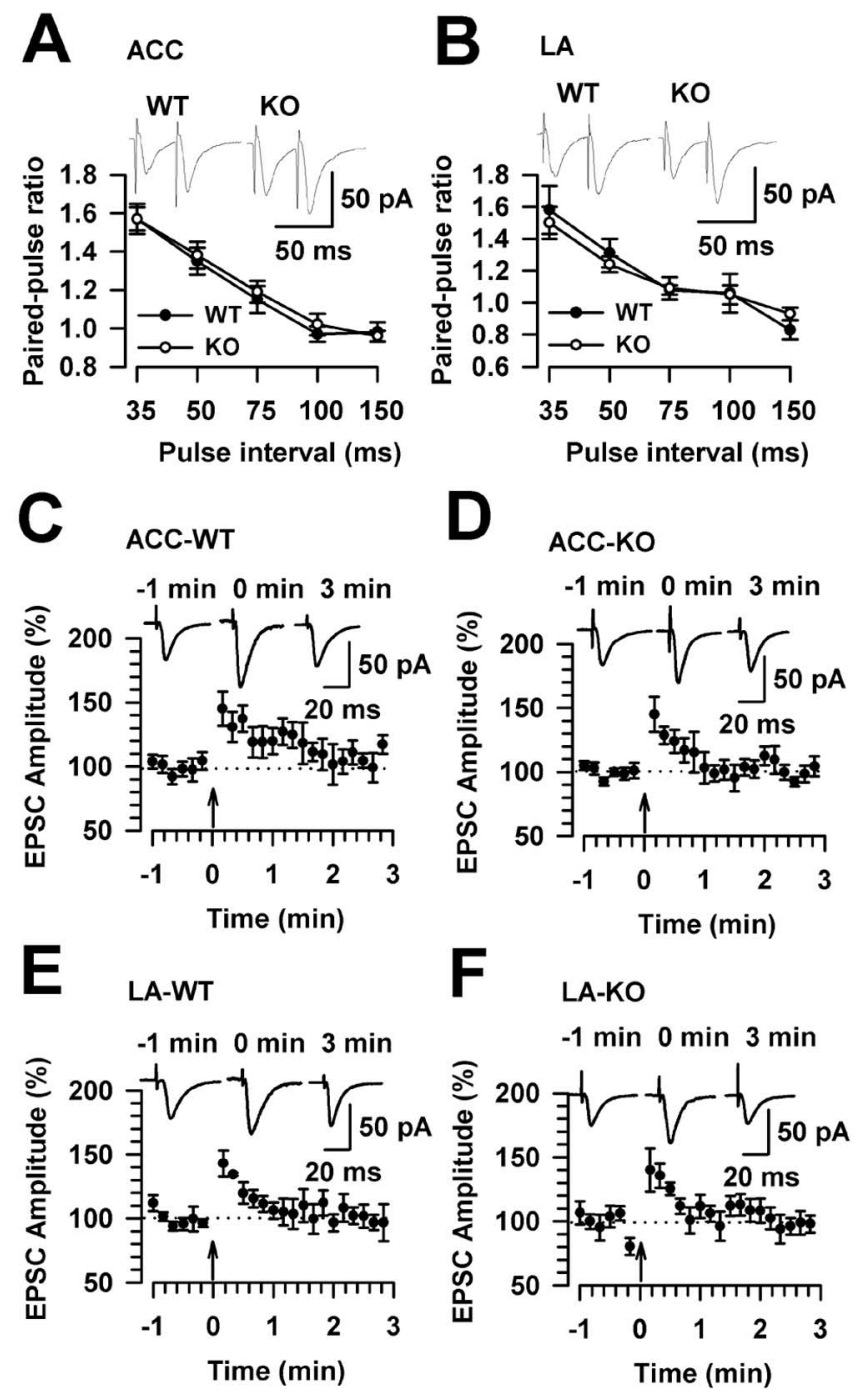

Figure 3. Normal short-term synaptic potentiation in FMR1 KO mice. $A, P P F$ induced at five different intervals did not differ in FMR1 WT mice ( $n=6$ slices/4 mice) and K0 mice ( $n=9$ slices/5 mice) in the ACC. $\boldsymbol{B}$, PPF induced at five different intervals did not differ in FMR1 WT mice ( $n=5$ slices $/ 3$ mice) and KO mice ( $n=7$ slices $/ 4$ mice) in the LA. The insets show sample traces with a paired-pulse interval of $50 \mathrm{~ms}$. C, Posttetanic potentiation in the ACC from WT mice $(n=$ 6 slices $/ 4$ mice). D, Posttetanic potentiation in the ACC from FMR1 K0 mice ( $n=8$ slices $/ 5$ mice). $\boldsymbol{E}$, Posttetanic potentiation in the LA from WT mice ( $n=5$ slices $/ 3$ mice). $\boldsymbol{F}$, Posttetanic potentiation in the LA from FMR1 KO mice ( $n=7$ slices $/ 5$ mice). Posttetanic potentiation was induced by a $1 \mathrm{~s}, 100 \mathrm{~Hz}$ stimulus (arrows). $\mathbf{C}-\boldsymbol{F}$, Insets show sample traces at $-1,0$, and $3 \mathrm{~min}$ after training. Error bars indicate SE.

sion of LTP is accompanied by altered paired-pulse facilitation (PPF) (Zalutsky and Nicoll, 1990). To determine whether presynaptic mechanisms are involved in the loss of LTP in the ACC and LA in FMR1 KO mice, we measured the PPF ratio and posttetanic potentiation, which are also considered forms of shortterm synaptic plasticity. As shown in Figure 3, $A$ and $B$, PPF induced at five different intervals did not differ in WT and FMR1 KO mice in either the ACC or LA. Posttetanic potentiation was induced by a $1 \mathrm{~s}, 100 \mathrm{~Hz}$ stimulus. FMR1 KO mice exhibited normal posttetanic potentiation compared with WT mice in the ACC (Fig. 3C,D) and LA (Fig. $3 E, F$ ). Short-term synaptic plasticity in FMR1 KO mice appears normal, and presynaptic mechanisms do not seem to be involved in the loss of LTP in FMR1 KO mice. 


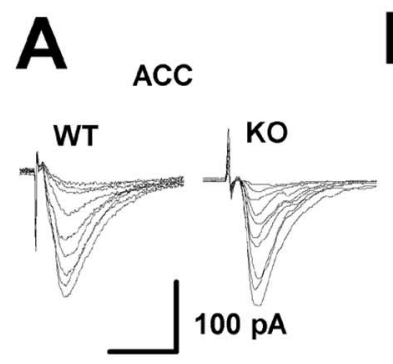

$20 \mathrm{~ms}$

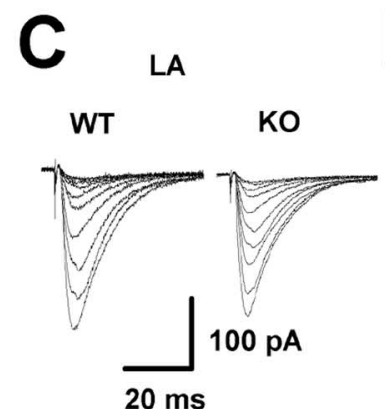

D

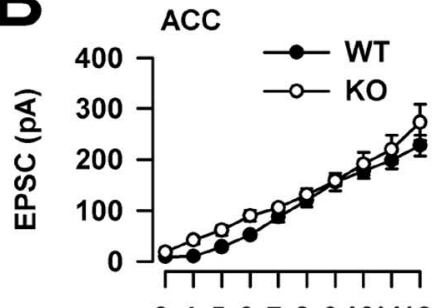

3456789101112

Stimulation density (V)
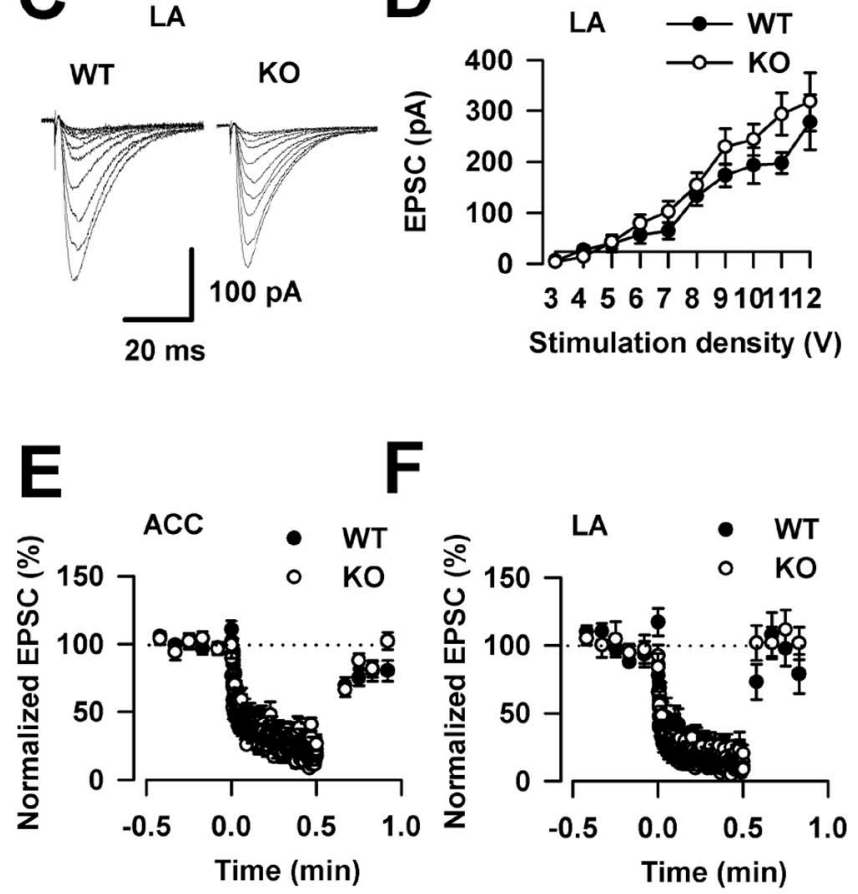

Figure 4. Normal synaptic transmission in FMR1 KO mice. $\boldsymbol{A}$, Sample traces show inputoutput relationship of AMPA receptor-mediated EPSCs in the ACC. $\boldsymbol{B}$, There were no differences in plots of input - output curves in the ACC between WT mice ( $n=8$ slices $/ 5$ mice) and FMR1 KO mice ( $n=6$ slices/4 mice). C, Sample traces show input- output relationships in the LA. $\boldsymbol{D}$, There were no differences in plots of input- output curves in the LA between WT mice $(n=7$ slices $/ 4$ mice) and FMR $1 \mathrm{KO}$ mice ( $n=6$ slices $/ 3$ mice). $E, A 10 \mathrm{~Hz}$ repetitive stimulation causes a pronounced activity-dependent depression. Responses to a $10 \mathrm{~Hz}$ repetitive stimulation overlap in the ACC between WT mice ( $n=5$ slices $/ 3$ mice) and FMR1 K0 mice ( $n=8$ slices $/ 5$ mice). $F$, Responses to a $10 \mathrm{~Hz}$ repetitive stimulation overlap in the LA between WT mice $(n=5$ slices $/ 3$ mice) and FMR1 KO mice ( $n=8$ slices/5 mice). Error bars indicate SE.

Synaptic transmission in the ACC and LA of FMR1 WT and KO mice

FMRP is believed to be important in the regulation of protein synthesis in synapses by providing a local source of newly synthesized proteins needed for synaptic function. FMR1 KO mice have dendritic abnormalities analogous to those in humans with more long, thin spines (Irwin et al., 2001; Nimchinsky et al., 2001). Experiments were performed to examine whether synaptic transmission was altered in FMR1 KO mice. First, the input-output relationship of AMPA receptor-mediated EPSCs was examined. As shown in Figure $4 A-D$, there were no differences in the inputoutput curves of ACC and LA synapses between WT and FMR1 KO mice. Next, to achieve a more global assessment of synaptic vesicle cycling, we used a protocol of repetitive stimulation at a physiological frequency (10 Hz for $30 \mathrm{~s}$ ) (Rosahl et al., 1995).
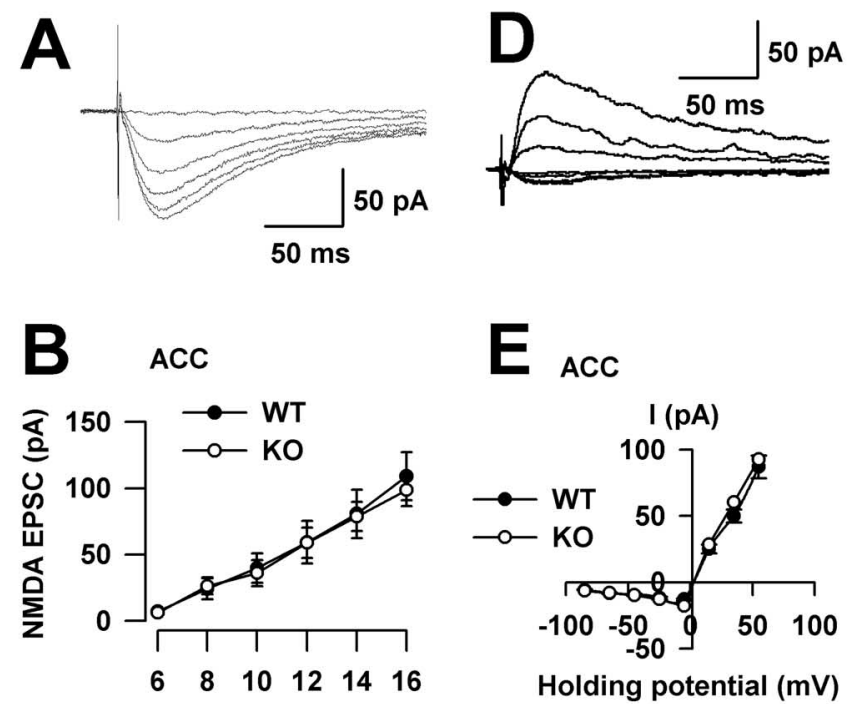

Stimulation density (V)
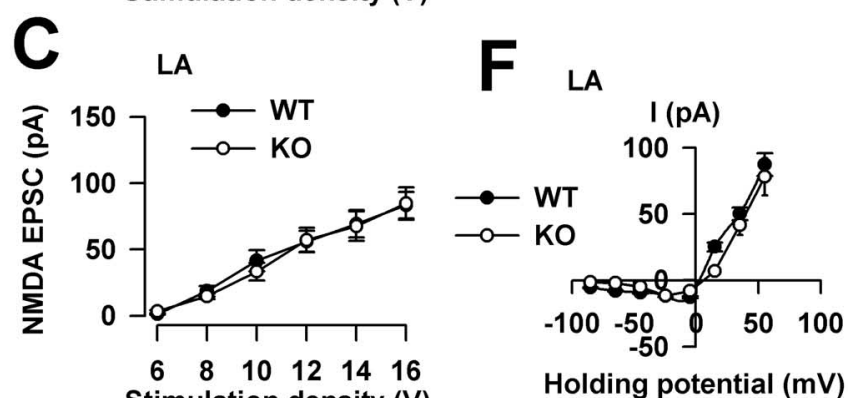

Stimulation density (V)

Holding potential $(\mathrm{mV})$

Figure 5. NMDAR-mediated EPSCS in FMR1 KO and WT mice. $A$, Sample trace showing the input- output relationship of NMDAR-mediated EPSCs in a WT ACC neuron. $\boldsymbol{B}$, There was no difference in the input- output curve of NMDAR-mediated EPSCs in the ACC between WT mice ( $n=5$ slices $/ 3$ mice) and FMR1 KO mice ( $n=5$ slices $/ 3$ mice). C, There was no difference in the input- output curve of NMDAR-mediated EPSCs in the LA between WT mice $(n=5$ slices $/ 3$ mice) and FMR1 K0 mice ( $n=5$ slices $/ 3$ mice). $D$, Sample trace showing NMDAR-mediated EPSCs evoked at holding potentials of $-85 \mathrm{mV}$ to approximately $+55 \mathrm{mV}$. $\boldsymbol{E}$, Current-voltage plots for NMDA receptor EPSCs between WT mice $(n=5$ slices $/ 3$ mice) and FMR1 K0 mice $(n=$ 5 slices $/ 3$ mice) in the ACC. F, Current-voltage plots for NMDA receptor EPSCs between WT mice ( $n=5$ slices $/ 3$ mice) and FMR1 KO mice ( $n=5$ slices $/ 3$ mice) in the LA. Error bars indicate SE.

After recording $(0.2 \mathrm{~Hz})$ the baseline for $30 \mathrm{~s}$, the application of $10 \mathrm{~Hz}$ repetitive stimulation, which causes a continuous decline of neurotransmitter release, resulted in a rapid and a pronounced activity-dependent depression. No differences were found in this assessment of synaptic vesicle cycles in ACC and LA synapses between WT and FMR1 KO mice (Fig. 4E,F). These results suggest that there are no differences in synaptic transmission in WT and FMR1 KO mice within these regions.

NMDA receptor-mediated EPSCs in the ACC and LA

To further explore the synaptic mechanisms behind the reduction of synaptic potentiation, we examined NMDA receptormediated EPSCs in the ACC and LA of FMR1 KO mice. As shown in Figure $5 A-C$, there were no differences in total NMDARmediated input-output curves in ACC or LA synapses between WT and FMR1 KO mice. Next, to examine the voltage dependence of NMDAR-meditated currents, we recorded synaptic responses in voltage-clamp mode over a range of membrane potentials from $-85 \mathrm{mV}$ to approximately $+55 \mathrm{mV}$ (Fig. 5D). The peak $I-V$ curve for the NMDAR-mediated currents was outwardly rectifying. In ACC neurons, the linear part of the $I-V$ curve had a 
A
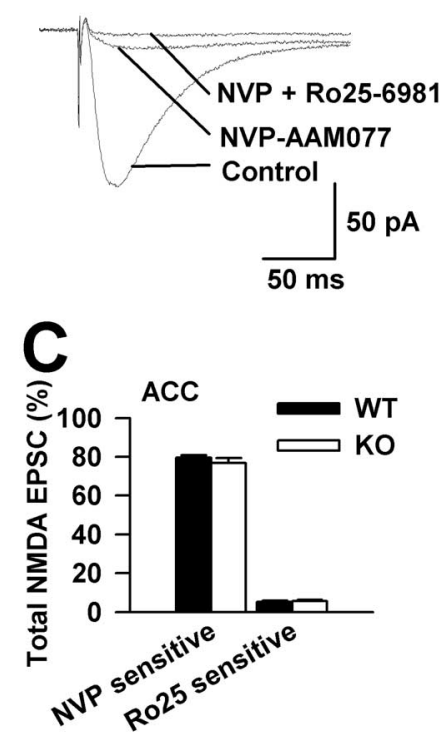

B

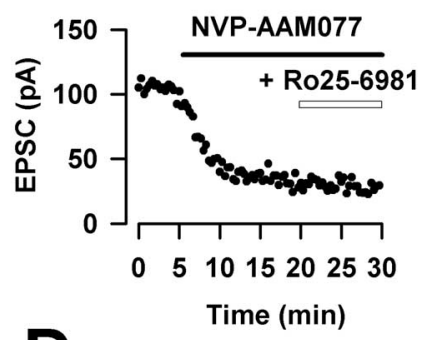

D

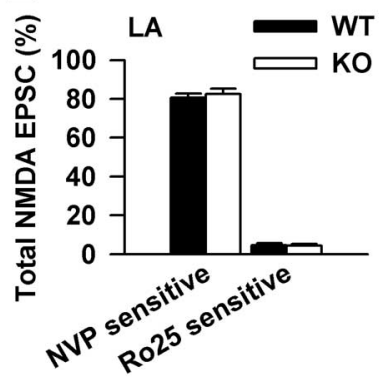

Figure 6. NR2A- and NR2B-containing NMDAR-mediated EPSC $\sin$ FMR1 K0 and WT mice. $\boldsymbol{A}$ Sample trace of NMDAR-mediated EPSCs recorded from one ACC neuron in WT mouse in saline solution, NVP-AAM077 (0.4 $\mu \mathrm{M})$, and after coapplication of R025-6981 $(0.3 \mu \mathrm{M})$. B, Time course of recording in $A$. C, NR2A- and NR2B-containing NMDAR-mediated EPSCs were similar in the ACC of FMR $1 \mathrm{KO}$ mice ( $n=7$ slices $/ 4$ mice) and WT mice ( $n=6$ slices $/ 3$ mice). $D, N R 2 A$ - and NR2B-containing NMDAR-mediated EPSCs were similar in the LA of FMR1 KO mice ( $n=5$ slices/3 mice) and WT mice ( $n=6$ slices/4 mice). NR2A current is a subtraction of the NR2Asensitive component from the total NMDAR EPSCs; NR2B current is a subtraction of the NR2Bsensitive component after NVP-AAM077 perfusion. NVP, NVP-AAM077; Ro25, R025-6981. Error bars indicate SE.

reversal potential of $2.5 \pm 0.5 \mathrm{mV}(n=5$ slices $/ 3$ mice $)$ and $2.9 \pm$ $0.5 \mathrm{mV}(n=5$ slices/ 3 mice $)$ in WT and FMR1 KO mice, respectively $(p>0.05)$ (Fig. $5 E$ ). Similar results were found in LA neurons. The linear part of the $I-V$ curve had a reversal potential of $8.0 \pm 2.6 \mathrm{mV}(n=5$ slices $/ 3$ mice $)$ and $7.4 \pm 2.1 \mathrm{mV}(n=5$ slices/ 3 mice) in WT and FMR1 KO mice, respectively $(p>0.05)$ (Fig. $5 F$ ). The formation of functional NMDARs requires a combination of NR1, an essential channel-forming subunit, and at least one NR2 subunit. The NR2A and NR2B subunits predominate in the forebrain, and these subunits determine many of the properties of the NMDAR (Loftis and Janowsky, 2003). Here, we used selective pharmacological antagonists for NR2A and NR2B to examine synaptically induced NMDAR-mediated EPSCs. Bath application of a selective NMDAR NR2A subunit antagonist,

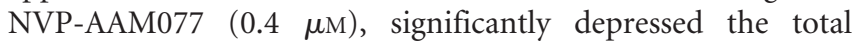
NMDAR-mediated currents (called the NVP-AAM077-sensitive component). Furthermore, the addition of Ro25-6981 (0.3 $\mu \mathrm{M})$, an NR2B blocker, produced an additional reduction (called the Ro25-6981-sensitive component) (Fig. 6A,B). Compared with WT mice, NR2A- and NR2B-containing NMDAR-mediated EPSCs were similar in FMR1 KO mice in the ACC (NVP-AAM077sensitive: WT, $79.5 \pm 1.3 \%, n=6$ slices $/ 3$ mice; $\mathrm{KO}, 76.7 \pm 2.7 \%$, $n=7$ slices/4 mice; Ro25-6981-sensitive: WT, $5.2 \pm 0.6, n=6$ slices $/ 3$ mice; KO, $5.6 \pm 0.7 \%, n=7$ slices $/ 3$ mice) (Fig. $6 C$ ) and in the LA (NVP-AAM077-sensitive: WT, $80.5 \pm 2.1 \%, n=6$ slices/4 mice; KO, $82.4 \pm 2.8 \%, n=5$ slices/3 mice; Ro25-6981sensitive: WT, $4.7 \pm 1.0 \%, n=6$ slices $/ 4$ mice; $\mathrm{KO}, 4.4 \pm 0.9 \%$, $n=5$ slices $/ 3$ mice) (Fig. $6 D$ ). These results suggest that there are no differences in NMDA receptor-mediated synaptic transmission in WT and FMR1 KO mice within these regions.

\section{Discussion}

The creation of a mouse model for fragile X syndrome has provided a useful tool for studying the complex mechanisms of this disease. Some behavioral phenotypes of the FMR1 KO mouse include an increase in locomotor activity, mild spatial learning deficits, and diminished responses to acoustic startle stimuli (Table 1). It is difficult to define a role for FMR1 in auditory and contextual fear conditioning, because results from these studies are conflicting (Table 1). One explanation for the variability in the observed phenotypes may be attributable to the genetic background of wild-type and knock-out mice (Dobkin et al., 2000). In the present study, we demonstrate that trace fear memory was impaired in FMR1 KO mice, indicating that the FMR1 gene is important in attention-based associative learning. The impaired freezing response of FMR1 KO mice was not caused by hyperactivity, altered anxiety levels, or an insensitivity to pain, because FMR1 KO mice showed normal baseline freezing, normal locomotor activity, normal anxiety-like behavior, and normal responses in the hotplate and tail-flick reflex. Furthermore, we show that LTP was significantly decreased in the ACC and LA of FMR1 KO mice, whereas short-term synaptic plasticity and basal synaptic transmission were similar to WT mice. This is the first study, to our knowledge, to correlate a behavioral phenotype relevant to the symptoms of fragile $\mathrm{X}$ syndrome with alterations in synaptic plasticity in the ACC and amygdala.

Trace fear conditioned learning requires an intact medial prefrontal cortex, ACC, and hippocampus (Huerta et al., 2000; Blank et al., 2003; Han et al., 2003; Runyan et al., 2004). Consistent with the defect in trace fear conditioning seen in FMR1 KO mice, patients with fragile $\mathrm{X}$ syndrome have abnormal activation patterns in the ventromedial prefrontal cortex, ACC, and hippocampus (Menon et al., 2004). Trace fear conditioning requires the subject to sustain attention during the trace interval (Clark and Squire, 1998; Han et al., 2003). Because children with fragile $\mathrm{X}$ exhibit behavioral problems of severe inattention (Fryns et al., 1984; Baumgardner et al., 1995) and many are diagnosed with ADHD (Cornish et al., 2004), the use of trace fear conditioning may be more sensitive to the mild learning deficits in FMR1 KO mice compared with traditional measures of conditioned fear memory.

Animal models for fragile $\mathrm{X}$ have been developed in mice (Bakker, 1994; Gao, 2002; Bakker and Oostra, 2003; Kooy, 2003), Drosophila (Wan et al., 2000), and zebrafish (van 't Padje et al., 2005). An FMRP ortholog has been identified in zebrafish and found to be expressed in the brain. This animal model may be especially useful in studying the role of FMRP during embryonic development (van 't Padje et al., 2005). Many of the phenotypes uncovered from studies in Drosophila mirror human symptoms of fragile X. Macro-orchidism, alterations in locomotor activity, and changes in synapse structure are fragile $\mathrm{X}$ phenotypes shared among mouse, human, and Drosophila (Bakker, 1994; Comery et al., 1997; Greenough et al., 2001; Zhang et al., 2001, 2004; Kooy, 2003). Although severe locomotor defects (Zhang et al., 2001) may hinder the assessment of learning and memory deficits in Drosophila models (Zhang and Broadie, 2005), studies have reported alterations in the morphology of learning and memoryrelated mushroom bodies and in courtship behavior (Michel et al., 2004; McBride et al., 2005).

Behavioral phenotyping of genetically modified animals may be confounded by developmental defects that would affect the motor responses used to quantitate behavioral changes. In this study, we assessed locomotor activity in the open field to deter- 
mine whether changes in activity could account for a reduction in the freezing response seen in the trace fear memory experiments. In contrast to previous reports (Peier et al., 2000; Mineur et al., 2002; Kooy, 2003), we found no alteration in locomotor activity in the open field between FMR1 WT and KO mice (Fig. 1C). This result agrees with a previous study (Nielsen et al., 2002) and suggests that hyperactivity did not influence the recording of freezing behavior. In addition, there was no difference in exploration of the elevated plus maze in FMR1 KO mice, signifying unaltered levels of anxiety-related behavior. Importantly, hotplate and tail-flick responses were similar between FMR1 WT and $\mathrm{KO}$ mice, indicating that acute responses to noxious stimuli are not dependent on the expression of FMRP.

Normal hippocampal function is required for the formation of classic fear memory (Shimizu et al., 2000; Debiec et al., 2002). Four independent studies showed that LTP in the CA1 region of the hippocampus was unaltered in FMR1 KO mice (Godfraind et al., 1996; Paradee et al., 1999; Li et al., 2002), despite reported deficits in hippocampal-dependent spatial memory and contextual fear memory (D’Hooge et al., 1997; Paradee et al., 1999; Van Dam et al., 2000; Bakker and Oostra, 2003) (Table 1). Another study reported a reduction in LTP within the somatosensory cortex of FMR1 KO mice (Li et al., 2002). Synaptic changes within the ACC and LA have not been reported in FMR1 KO mice despite the importance of both brain regions in learning and memory. Contrary to previous reports of unaltered LTP in the hippocampus (measured by field recording) (Table 1), whole-cell patch clamp recordings revealed that LTP was reduced in both the ACC and LA of FMR1 KO mice.

The present study is the first to examine LTP in the amygdala of FMR1 KO mice. The LA nucleus receives projections from the cortex (cortico-input) and the thalamus (thalamo-input), playing an essential role in the learning process of fear conditioning (McKernan and Shinnick-Gallagher, 1997; Rogan et al., 1997; Tsvetkov et al., 2002; Rodrigues et al., 2004; Dityatev and Bolshakov, 2005). Our finding that LTP is decreased in the LA of FMR1 $\mathrm{KO}$ mice is consistent with the defect in amygdala-dependent auditory fear conditioning reported previously (Paradee et al., 1999).

Defects in FMRP expression have been shown to cause dendritic abnormalities such as long, thin, and overabundant spines (Irwin et al., 2001; Nimchinsky et al., 2001). However, synaptic transmission was normal in the ACC and LA of FMR1 KO mice, as demonstrated by normal input-output curves and synaptic vesicle cycle function. Paired-pulse facilitation and posttetanic potentiation are considered forms of short-term synaptic plasticity. Our results show normal short-term synaptic plasticity in FMR1 KO mice and indicate that presynaptic mechanisms are not involved in the loss of LTP. The input-output relationship of NMDA receptor-mediated currents and the percentage of NR2A- and NR2B-mediated currents suggest that synaptic NMDAR-mediated currents do not differ between FMR1 WT and $\mathrm{KO}$ mice. What is the mechanism responsible for the defect in LTP found in the ACC and LA of FMR1 KO mice? One possible explanation is that FMRP contributes to synaptic potentiation through interaction with postsynaptic mechanisms related to AMPA receptor regulation. FMRP may interact with various protein kinases and signaling proteins involved in AMPA receptor interactions that are important for LTP. FMR1 KO mice, which lack FMRP expression, may exhibit a defect in AMPA receptor function that prohibits the establishment of LTP. Changes in metabotropic glutamate receptor-mediated signaling pathways may also be important, because it has been reported that FMRP is produced at synapses after stimulation of metabotropic glutamate receptors (Weiler and Greenough, 1999), and metabotropic glutamate receptor-dependent long-term depression is significantly altered in the hippocampus of FMR1 KO mice (Huber et al., 2002).

In this study, we show that FMR1 KO mice are impaired at acquiring trace fear memory, suggesting that the deletion of FMR1 affects the ability to sustain attention in a manner that is needed to learn the trace conditioning. This defect is consistent with deficits in attention reported in fragile X patients. Moreover, we use whole-cell patch-clamp recording to show that LTP is decreased in both the ACC and LA of FMR1 KO mice. This is consistent with the impairment in trace fear conditioning and the defect in amygdala-dependent auditory fear conditioning reported previously (Paradee et al., 1999). In summary, we show that a defect in associative learning correlates with changes in synaptic plasticity within the ACC of FMR1 KO mice. This study suggests that plastic changes outside of the hippocampus may be involved in the etiology of fragile X syndrome.

\section{References}

Bakker CE (1994) Fmr1 knockout mice: a model to study fragile X mental retardation. The Dutch-Belgian Fragile X Consortium. Cell 78:23-33.

Bakker CE, Oostra BA (2003) Understanding fragile X syndrome: insights from animal models. Cytogenet Genome Res 100:111-123.

Baumgardner TL, Reiss AL, Freund LS, Abrams MT (1995) Specification of the neurobehavioral phenotype in males with fragile $\mathrm{X}$ syndrome. Pediatrics 95:744-752.

Blank T, Nijholt I, Kye MJ, Radulovic J, Spiess J (2003) Small-conductance, $\mathrm{Ca}^{2+}$-activated $\mathrm{K}^{+}$channel SK3 generates age-related memory and LTP deficits. Nat Neurosci 6:911-912.

Bliss TV, Collingridge GL (1993) A synaptic model of memory: long-term potentiation in the hippocampus. Nature 361:31-39.

Clark RE, Squire LR (1998) Classical conditioning and brain systems: the role of awareness. Science 280:77-81.

Comery TA, Harris JB, Willems PJ, Oostra BA, Irwin SA, Weiler IJ, Greenough WT (1997) Abnormal dendritic spines in fragile X knockout mice: maturation and pruning deficits. Proc Natl Acad Sci USA 94:5401-5404.

Cornish K, Sudhalter V, Turk J (2004) Attention and language in fragile X. Ment Retard Dev Disabil Res Rev 10:11-16.

Debiec J, LeDoux JE, Nader K (2002) Cellular and systems reconsolidation in the hippocampus. Neuron 36:527-538.

D’Hooge R, Nagels G, Franck F, Bakker CE, Reyniers E, Storm K, Kooy RF, Oostra BA, Willems PJ, De Deyn PP (1997) Mildly impaired water maze performance in male Fmr1 knockout mice. Neuroscience 76:367-376.

Dityatev AE, Bolshakov VY (2005) Amygdala, long-term potentiation, and fear conditioning. Neuroscientist 11:75-88.

Dobkin C, Rabe A, Dumas R, El Idrissi A, Haubenstock H, Brown WT (2000) Fmrl knockout mouse has a distinctive strain-specific learning impairment. Neuroscience 100:423-429.

Eichler EE, Holden JJ, Popovich BW, Reiss AL, Snow K, Thibodeau SN, Richards CS, Ward PA, Nelson DL (1994) Length of uninterrupted CGG repeats determines instability in the FMR1 gene. Nat Genet 8:88-94.

Feng Y, Zhang F, Lokey LK, Chastain JL, Lakkis L, Eberhart D, Warren ST (1995) Translational suppression by trinucleotide repeat expansion at FMR1. Science 268:731-734.

Frankland PW, Bontempi B, Talton LE, Kaczmarek L, Silva AJ (2004) The involvement of the anterior cingulate cortex in remote contextual fear memory. Science 304:881-883.

Fryns JP, Jacobs J, Kleczkowska A, van den Berghe H (1984) The psychological profile of the fragile X syndrome. Clin Genet 25:131-134.

Gao FB (2002) Understanding fragile X syndrome: insights from retarded flies. Neuron 34:859-862.

Godfraind JM, Reyniers E, De Boulle K, D’Hooge R, De Deyn PP, Bakker CE, Oostra BA, Kooy RF, Willems PJ (1996) Long-term potentiation in the hippocampus of fragile X knockout mice. Am J Med Genet 64:246-251.

Greenough WT, Klintsova AY, Irwin SA, Galvez R, Bates KE, Weiler IJ (2001) Synaptic regulation of protein synthesis and the fragile $\mathrm{X}$ protein. Proc Natl Acad Sci USA 98:7101-7106. 
Hagerman RJ, Staley LW, O'Conner R, Lugenbeel K, Nelson D, McLean SD, Taylor A (1996) Learning-disabled males with a fragile X CGG expansion in the upper premutation size range. Pediatrics 97:122-126.

Han CJ, O’Tuathaigh CM, van Trigt L, Quinn JJ, Fanselow MS, Mongeau R, Koch C, Anderson DJ (2003) Trace but not delay fear conditioning requires attention and the anterior cingulate cortex. Proc Natl Acad Sci USA 100:13087-13092.

Hess G, Jacobs KM, Donoghue JP (1994) N-Methyl-D-aspartate receptor mediated component of field potentials evoked in horizontal pathways of rat motor cortex. Neuroscience 61:225-235.

Huber KM, Gallagher SM, Warren ST, Bear MF (2002) Altered synaptic plasticity in a mouse model of fragile $\mathrm{X}$ mental retardation. Proc Natl Acad Sci USA 99:7746-7750.

Huerta PT, Sun LD, Wilson MA, Tonegawa S (2000) Formation of temporal memory requires NMDA receptors within CA1 pyramidal neurons. Neuron 25:473-480.

Irwin SA, Patel B, Idupulapati M, Harris JB, Crisostomo RA, Larsen BP, Kooy F, Willems PJ, Cras P, Kozlowski PB, Swain RA, Weiler IJ, Greenough WT (2001) Abnormal dendritic spine characteristics in the temporal and visual cortices of patients with fragile-X syndrome: a quantitative examination. Am J Med Genet 98:161-167.

Jin P, Warren ST (2003) New insights into fragile X syndrome: from molecules to neurobehaviors. Trends Biochem Sci 28:152-158.

Ko S, Zhao MG, Toyoda H, Qiu CS, Zhuo M (2005) Altered behavioral responses to noxious stimuli and fear in glutamate receptor 5 (GluR5)- or GluR6-deficient mice. J Neurosci 25:977-984.

Kooy RF (2003) Of mice and the fragile X syndrome. Trends Genet 19:148-154.

Li J, Pelletier MR, Perez Velazquez JL, Carlen PL (2002) Reduced cortical synaptic plasticity and GluR1 expression associated with fragile X mental retardation protein deficiency. Mol Cell Neurosci 19:138-151.

Loftis JM, Janowsky A (2003) The $N$-methyl-D-aspartate receptor subunit NR2B: localization, functional properties, regulation, and clinical implications. Pharmacol Ther 97:55-85.

Malenka RC, Nicoll RA (1993) NMDA-receptor-dependent synaptic plasticity: multiple forms and mechanisms. Trends Neurosci 16:521-527.

Manns JR, Clark RE, Squire LR (2000) Awareness predicts the magnitude of single-cue trace eyeblink conditioning. Hippocampus 10:181-186.

McBride SM, Choi CH, Wang Y, Liebelt D, Braunstein E, Ferreiro D, Sehgal A, Siwicki KK, Dockendorff TC, Nguyen HT, McDonald TV, Jongens TA (2005) Pharmacological rescue of synaptic plasticity, courtship behavior, and mushroom body defects in a Drosophila model of fragile X syndrome. Neuron 45:753-764.

McKernan MG, Shinnick-Gallagher P (1997) Fear conditioning induces a lasting potentiation of synaptic currents in vitro. Nature 390:607-611.

Menon V, Leroux J, White CD, Reiss AL (2004) Frontostriatal deficits in fragile X syndrome: relation to FMR1 gene expression. Proc Natl Acad Sci USA 101:3615-3620.

Michel CI, Kraft R, Restifo LL (2004) Defective neuronal development in the mushroom bodies of Drosophila fragile X mental retardation $1 \mathrm{mu}-$ tants. J Neurosci 24:5798-5809.

Mineur YS, Sluyter F, de Wit S, Oostra BA, Crusio WE (2002) Behavioral and neuroanatomical characterization of the Fmr1 knockout mouse. Hippocampus 12:39-46.

Nicoll RA, Malenka RC (1995) Contrasting properties of two forms of longterm potentiation in the hippocampus. Nature 377:115-118.

Nielsen DM, Derber WJ, McClellan DA, Crnic LS (2002) Alterations in the auditory startle response in Fmr1 targeted mutant mouse models of fragile X syndrome. Brain Res 927:8-17.

Nimchinsky EA, Oberlander AM, Svoboda K (2001) Abnormal development of dendritic spines in FMR1 knock-out mice. J Neurosci 21:5139-5146.

Oberle I, Rousseau F, Heitz D, Kretz C, Devys D, Hanauer A, Boue J, Bertheas MF, Mandel JL (1991) Instability of a 550-base pair DNA segment and abnormal methylation in fragile X syndrome. Science 252:1097-1102.

Paradee W, Melikian HE, Rasmussen DL, Kenneson A, Conn PJ, Warren ST (1999) Fragile X mouse: strain effects of knockout phenotype and evidence suggesting deficient amygdala function. Neuroscience 94:185-192.
Peier AM, McIlwain KL, Kenneson A, Warren ST, Paylor R, Nelson DL (2000) (Over)correction of FMR1 deficiency with YAC transgenics: behavioral and physical features. Hum Mol Genet 9:1145-1159.

Pieretti M, Zhang FP, Fu YH, Warren ST, Oostra BA, Caskey CT, Nelson DL (1991) Absence of expression of the FMR-1 gene in fragile X syndrome. Cell 66:817-822.

Rodrigues SM, Schafe GE, LeDoux JE (2004) Molecular mechanisms underlying emotional learning and memory in the lateral amygdala. Neuron 44:75-91.

Rogan MT, Staubli UV, LeDoux JE (1997) Fear conditioning induces associative long-term potentiation in the amygdala. Nature 390:604-607.

Rosahl TW, Spillane D, Missler M, Herz J, Selig DK, Wolff JR, Hammer RE, Malenka RC, Sudhof TC (1995) Essential functions of synapsins I and II in synaptic vesicle regulation. Nature 375:488-493.

Runyan JD, Moore AN, Dash PK (2004) A role for prefrontal cortex in memory storage for trace fear conditioning. J Neurosci 24:1288-1295.

Shimizu E, Tang YP, Rampon C, Tsien JZ (2000) NMDA receptordependent synaptic reinforcement as a crucial process for memory consolidation. Science 290:1170-1174.

Siomi H, Choi M, Siomi MC, Nussbaum RL, Dreyfuss G (1994) Essential role for KH domains in RNA binding: impaired RNA binding by a mutation in the $\mathrm{KH}$ domain of FMR1 that causes fragile $\mathrm{X}$ syndrome. Cell 77:33-39.

Tsvetkov E, Carlezon WA, Benes FM, Kandel ER, Bolshakov VY (2002) Fear conditioning occludes LTP-induced presynaptic enhancement of synaptic transmission in the cortical pathway to the lateral amygdala. Neuron 34:289-300.

Van Dam D, D'Hooge R, Hauben E, Reyniers E, Gantois I, Bakker CE, Oostra BA, Kooy RF, De Deyn PP (2000) Spatial learning, contextual fear conditioning and conditioned emotional response in Fmr1 knockout mice. Behav Brain Res 117:127-136.

van 't Padje S, Engels B, Blonden L, Severijnen LA, Verheijen F, Oostra BA, Willemsen R (2005) Characterisation of Fmrp in zebrafish: evolutionary dynamics of the fmrl gene. Dev Genes Evol 215:198-206.

Verkerk AJ, Pieretti M, Sutcliffe JS, Fu YH, Kuhl DP, Pizzuti A, Reiner O, Richards S, Victoria MF, Zhang FP, Eussen BE, van Ommen G-J, Blonden LAJ, Riggins GJ, Chastain JL, Kunst CB, Galjaard H, Caskey CT, Nelson DL, Oostra BA, et al. (1991) Identification of a gene (FMR-1) containing a CGG repeat coincident with a breakpoint cluster region exhibiting length variation in fragile X syndrome. Cell 65:905-914.

Wan L, Dockendorff TC, Jongens TA, Dreyfuss G (2000) Characterization of dFMR1, a Drosophila melanogaster homolog of the fragile X mental retardation protein. Mol Cell Biol 20:8536-8547.

Wei F, Li P, Zhuo M (1999) Loss of synaptic depression in mammalian anterior cingulate cortex after amputation. J Neurosci 19:9346-9354.

Weiler IJ, Greenough WT (1999) Synaptic synthesis of the fragile X protein: possible involvement in synapse maturation and elimination. Am J Med Genet 83:248-252.

Weiler IJ, Spangler CC, Klintsova AY, Grossman AW, Kim SH, BertainaAnglade V, Khaliq H, de Vries FE, Lambers FA, Hatia F, Base CK, Greenough WT (2004) Fragile X mental retardation protein is necessary for neurotransmitter-activated protein translation at synapses. Proc Natl Acad Sci USA 101:17504-17509.

Willemsen R, Oostra BA, Bassell GJ, Dictenberg J (2004) The fragile X syndrome: from molecular genetics to neurobiology. Ment Retard Dev Disabil Res Rev 10:60-67.

Zalutsky RA, Nicoll RA (1990) Comparison of two forms of long-term potentiation in single hippocampal neurons. Science 248:1619-1624.

Zhang YQ, Broadie K (2005) Fathoming fragile X in fruit flies. Trends Genet 21:37-45.

Zhang YQ, Bailey AM, Matthies HJ, Renden RB, Smith MA, Speese SD, Rubin GM, Broadie K (2001) Drosophila fragile X-related gene regulates the MAP1B homolog Futsch to control synaptic structure and function. Cell 107:591-603.

Zhang YQ, Matthies HJ, Mancuso J, Andrews HK, Woodruff III E, Friedman D, Broadie K (2004) The Drosophila fragile X-related gene regulates axoneme differentiation during spermatogenesis. Dev Biol 270:290-307. 